\title{
REVIEW
}

\section{Quantitative neuropathological assessment to investigate cerebral multi-morbidity}

\author{
Johannes Attems ${ }^{1 *}$, Janna H Neltner ${ }^{2}$ and Peter T Nelson ${ }^{2}$
}

\begin{abstract}
The aging brain is characterized by the simultaneous presence of multiple pathologies, and the prevalence of cerebral multi-morbidity increases with age. To understand the impact of each subtype of pathology and the combined effects of cerebral multi-morbidity on clinical signs and symptoms, large clinico-pathological correlative studies have been performed. However, such studies are often based on semi-quantitative assessment of neuropathological hallmark lesions. Here, we discuss some of the new methods for high-throughput quantitative neuropathological assessment. These methods combine increased quantitative rigor with the added technical capacity of computers and networked analyses. There are abundant new opportunities - with specific techniques that include slide scanners, automated microscopes, and tissue microarrays - and also potential pitfalls. We conclude that quantitative and digital neuropathologic approaches will be key resources to further elucidate cerebral multi-morbidity in the aged brain and also hold the potential for changing routine neuropathologic diagnoses.
\end{abstract}

\section{Cerebral multi-morbidity}

It is becoming increasingly clear that, as a rule, the aging brain is characterized by the simultaneous presence of multiple neuropathological lesions rather than the hallmark lesion(s) of a single age-associated neurodegenerative disease [1]. Moreover, the prevalence of this cerebral multi-morbidity increases with age, and postmortem studies indicate that, in brains of demented individuals over 80 years of age, the presence of only one, single disease is a rare finding [2-7]. More details regarding the prevalence of mixed pathologies can be found in the article by Rahimi and Kovacs in the present review series of Alzheimer's Research \& Therapy [8]. Alzheimer's disease (AD) in particular often presents with comorbid processes, including cerebrovascular disease, Lewy body (LB) pathology, argyrophilic grain disease, transactivation response DNA binding protein $43 \mathrm{kDa}$ (TDP-43) pathology, and hippocampal sclerosis, and about two-thirds of aged human brains contain substantial non-AD pathology [9-11]. Indeed, in $A D$ that is neuropathologically characterized by amyloid-beta $(A \beta)$ and tau pathology (hyperphosphorylated tau), LB pathology ( $\alpha$-synuclein) is present in up to $43 \%[1,12]$ (AD with

\footnotetext{
*Correspondence: j.attems@ncl.ac.uk

'Institute of Neuroscience, Newcastle University, Campus for Ageing and Vitality, Newcastle upon Tyne NE4 5PL, UK

Full list of author information is available at the end of the article
}

LBs restricted to the amygdala is considered a distinct form of $\alpha$-synucleinopathy [12]) and severe cerebrovascular lesions are observed in up to 20\% [2] of cases, respectively. TDP-43 pathology often but not invariably restricted to the amygdala and granule cell layer of the dentate gyrus and entorhinal cortex is present in up to 57\% [11,13-15], and recently Josephs and colleagues [15] demonstrated that TDP-43 is an important factor in the manifestation of clinico-imaging features of $\mathrm{AD}$. In $\mathrm{LB}$ disease that is characterized by $\alpha$-synuclein pathology, we found $A \beta$ pathology in $95 \%$ of cases, considerable tau pathology (Braak stages V/VI) in 55\%, and various degrees of cerebrovascular pathology in 75\% [16]. Both A $\beta$ pathology (semi-quantitative scores [17]) and tau pathology (Braak stages [18]) correlated with LB pathology, and co-localization between hyperphosphorylated tau and $\alpha$-synuclein has been reported [12,17]. Pure vascular dementia without additional lesions is rare (for example, $12.3 \%$ in [4]), and frequently additional AD pathology is present. Whereas the common presence of neuropathologic comorbidities has been described in many autopsy series, the clinical diagnosis of multiple neurodegenerative pathologies in one single patient remains challenging and additional pathologies are often clinically unnoticed [19]. This may partially be due to a lack of clinico-pathological correlative studies that identified subtle clinical signs and 
symptoms that could point toward additional concomitant pathologies.

\section{Quantitative neuropathological assessment}

Clinico-pathological correlative studies are frequently based on semi-quantitative data and ordinal-type parameters to define the amount of pathology present in a given postmortem brain. These semi-quantitative data are usually provided on standardized four-tiered ordinal scales: absent, mild, moderate, and severe (for example, for tau [20] and $\alpha$-synuclein [21]). Although such semi-quantitative data are very useful for providing the neuropathological diagnosis, they often inaccurately reflect the actual amount of pathology present and this has major implications when data from large clinico-pathological correlative studies are entered into databases, since cases that might actually differ quite considerably regarding the amount of pathology fall into the same category. For example, we found that the amount of tau pathology in cases semiquantitatively scored 'severe' differed significantly when the actual area covered by immunopositivity was measured [1]. It is likely that new clinico-pathological phenotypes more accurately reflecting cerebral multi-morbidity would be identified by assessing the amount of pathology in a more quantitative way.

Indeed, in quantitatively assessing entorhinal and hippocampal tau pathology in a large cohort $(n=889)$ of both clinically and neuropathologically diagnosed $\mathrm{AD}$ cases, Murray and colleagues [22] identified typical AD as well as hippocampal sparing and limbic predominant subtypes of $\mathrm{AD}$. When comparing their quantitative neuropathological data with clinical findings, the authors found that these subtypes of AD differed in clinical presentation, age at onset, disease duration, and rate of cognitive decline from typical $\mathrm{AD}$ [22]. In a subsequent study, the authors found that magnetic resonance imaging (MRI) could predict these subtypes during life since hippocampal sparing AD showed the most severe cortical atrophy while the most severe medial temporal atrophy was observed in limbic predominant AD [23]. Of note, these AD subtypes and their associations with cortical atrophy in MRI would not have been identified if only semi-quantitative methodologies were employed, since all cases showed 'severe' entorhinal tau pathology. Only by the use of quantitative measurements did the 'severe' group show differences in the actual amount of pathology present. The authors more recently demonstrated that limbic predominant AD differed from neurofibrillary tangle (NFT) dominant dementia as the latter showed significantly less tau pathology in the mid-frontal cortex [24]. The authors also suggested that, in hippocampal sparing $\mathrm{AD}$, tau pathology may begin in the neocortex, since they found a fourfold increase in the amount of neocortical late-stage tau (antibody Ab39 to a conformational epitope in NFTs detecting late-stage tangles [25]) in hippocampal sparing AD compared with typical AD [24]. The findings from two large clinico-pathological correlative studies - the Nun Study and the Adult Changes in Thought (ACT) Study - indicated that 12\% (Nun Study) and 8\% (ACT Study) of non-demented subjects showed severe AD pathology reflected by Braak stage V-VI. However, quantitative assessment of NFT in both frontal and temporal cortices revealed that these non-demented subjects showed less NFT compared with demented subjects with Braak stage V-VI [26] and demonstrated a considerable range of pathology within Braak stage VI [27]. It is important to note that true 'end-stage' neurofibrillary pathology, measured with quantitative methods, has never been associated with an individual patient with ante-mortem intact cognition [27]. The density of neuritic plaques and NFTs rose significantly as a function of severity of dementia in subjects who were 60 to 80 years old, but no such association was found when subjects were over 90 years old [28], suggesting that additional factors contribute to the development of dementia in the oldest old.

The examples given above clearly indicate that quantitative neuropathological assessment allows the identification of clinico-pathological associations that are not detected by using semi-quantitative assessment alone. Moreover, given that quantitative assessment of tau pathology in $\mathrm{AD}$ cases points toward new clinico-pathological phenotypes [22], we assume that quantitative assessment of various neuropathological lesions in large autopsy cohorts would be beneficial to further elucidate possible mutual relationships between pathologies as well as their combined influence on the clinical picture. Hence, large clinicopathological correlative studies could identify subtle clinical features that point toward underlying pathologies. However, manual methods of quantitative assessment are timeconsuming since they involve either manual inspection of histological slides with visual counting of pathological lesions or importing individual images into an image analysis system for further analysis. Hence, automated methods for quantitative assessment might be helpful to investigate large study cohorts and to perform quantification in a routine setting.

\section{Automated quantitative neuropathological assessment}

Of note, the aim of this section is not to provide a detailed methodological description (which is outside the purview of this review article) or a comprehensive summary of all systems that might be currently used in other centers. Rather, we aim to give an overview of two methodologies for automated quantitative assessment that are currently used in our own laboratories, and we refer to our own published studies that successfully employed these methods. 


\section{Slide scanner and digital pathologic image analysis}

Digital pathology offers a valuable resource for quantitative pathology in neurodegenerative disease. In the recent consensus recommendation article sponsored by the National Institutes of Health and the Alzheimer's Association [29], it was noted that 'both quantitative and qualitative aspects of $\mathrm{AD}$ neuropathologic change have significance, but current diagnostic methods are not robustly quantitative and/or not systematically qualitative'. This statement confirms that more quantitative diagnostic methods are required in both the clinical and research settings. Toward those goals, digital pathology offers multiple benefits that surpass both semi-quantitative methods and manual counts. Digital algorithms offer a superior reproducibility and higher throughput performance that could enable a far more standardized approach to the assessment of $\mathrm{AD}$ neuropathologic changes (ADNCs). If individual centers began to use a standard algorithm for quantification, results could be used across institutions, exponentially increasing the statistical power available to all centers involved. Among the options for returning quantitative changes in pathologies, the digital approach is relatively efficient when it comes to manpower. With these algorithms, more pathology can be counted faster and more reproducibly than by manual inspection alone. In addition, more parameters can be rigorously examined, from staining intensity to plaque size and more as described below. As our use of this technology advances, it will open up a new understanding of the pathologies in human brain aging. Here, we provide some examples of results derived from the Aperio ScanScope (Leica Biosystems, Nussloch, Germany), which is used routinely at the University of Kentucky to document pathologic changes, including both neurodegenerative disease pathology and other subtypes of brain disease, that affect older persons. Over 100 slides can be scanned automatically in a batch. Although it does take additional time to scan the slide and set up the analysis windows (approximately 45 minutes to prepare and scan at $40 \times$ via the semi-automated method and an additional 510 minutes to select the analysis windows per slide), the bulk of the analysis work is done by the server alone. These analyses can be set up during the day and then allowed to run overnight without interruption (120 slides per night). In addition, neuropathologic expertise is not a requirement for this method, and we found that workers at various phases of training could all come up with very similar results in scoring ADNC quantification [30]. As the analysis algorithms are held constant, regardless of who sets up the windows, the data are consistent. In future endeavors, this could be expanded to involve algorithm sharing between institutions and thus improve the inter-rater reliability between the different research centers to help standardize the field of quantitative
ADNCs. In specific applications, digital pathology can be used for both novel discoveries and routine clinical duties. For example, although manually quantified ADNC numbers suggested that $A \beta$ plaque burden leveled off with increasing neurofibrillary pathology [31,32], we failed to identify that it actually decreases with increasing tau burden by our manual methods alone. However, this phenomenon could be well demonstrated with digital methods [30]. Additionally, it has previously been shown that apolipoprotein $\varepsilon 4$ alleles correlate with increased $A \beta$ plaque pathology [33-36]; however, we could demonstrate with digital methods that the plaque burden was partly related to larger plaques, not just more plaques [30]. These data may enable other new insights into the pathologic changes seen in $\mathrm{AD}$. In addition to the benefits for research, these data may be appreciated by clinicians who may desire more than a semi-quantitative idea about neuropathologic burden. Figure 1 shows a panel of photomicrographs depicting pathologic lesions that can be detected and quantified, along with a pathologic readout showing the data that are obtained for each patient and used for routine diagnostic practices at the University of Kentucky. The potential benefits of quantitative digital pathologic assessment extend beyond the description of 'inclusion bodies' that characterize many neurodegenerative diseases. This is important because many of the comorbid pathologies in the aged human brain involve additional subtypes of disease, including almost universal aging-related vascular, inflammatory, and metabolic changes [37-40]. As such, there are many additional new opportunities to study features of brain histomorphology that have been hitherto constrained by the intrinsic limitations of the human eye for detecting and quantifying geometric characteristics. Morphology of blood vessels - particularly, small blood vessels - provides an important subject area that confounded prior methodologies. Aged brains contain many subtypes of smallvessel changes, including cerebral amyloid angiopathy, arteriolosclerosis, expanded Virchow-Robin spaces, small hemorrhages with hemosiderinladen macrophages, and micro-infarcts $[4,41,42]$. A novel approach using the ScanScope digital pathologic algorithms was able to make novel discoveries [43], assessing the morphologic characteristics of capillaries (immunolabeled with an antibody raised against CD34) and arterioles (immunolabeled with an antibody raised against alpha-smooth muscle actin). This method was applied to demonstrate, in quantitative fashion, that hippocampal sclerosis of aging in humans [44] is associated with arteriolosclerosis in areas outside of the hippocampus [43]. This analysis would be difficult otherwise, given the lack of a rigorous universal definition of arteriolosclerosis. Figure 2 is a panel to illustrate some of the parameters that can be gleaned by the software when analyzing sections that are immunostained 


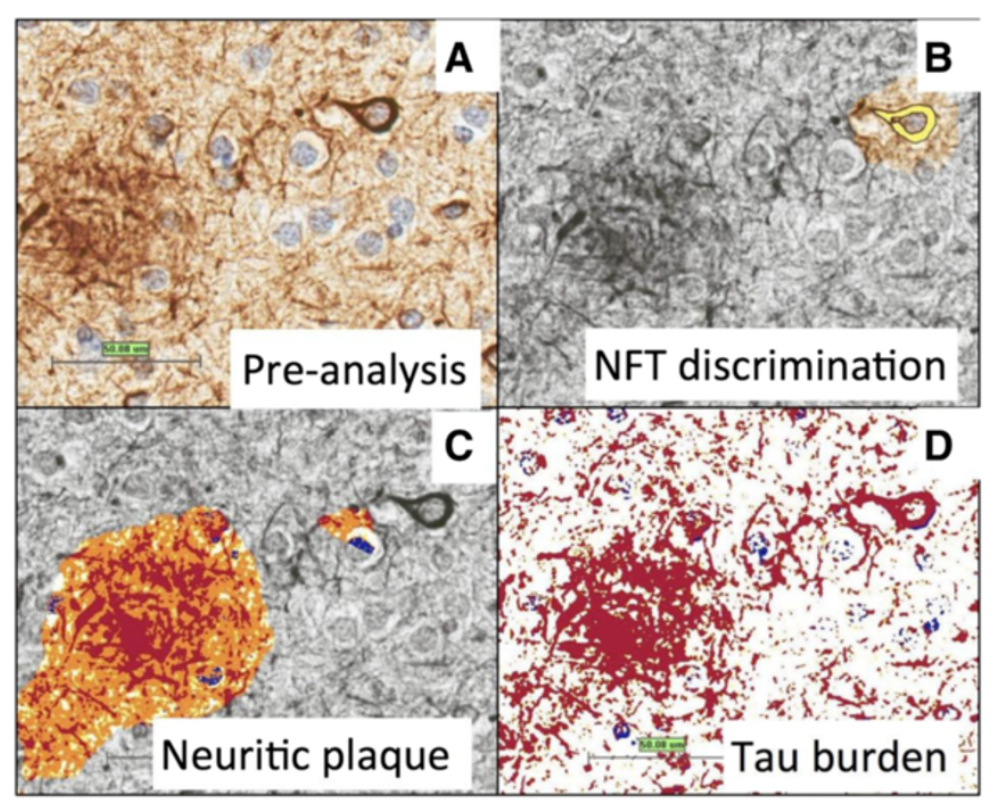

E Clinical diagnostic data for pathology report

\begin{tabular}{|c|c|c|c|c|c|}
\hline Limbic & Amyloid Burden & Amyloid & NFT density & NP burden & Tau burden \\
\hline Entorhinal Cortex & 7.87 & 14.56 & 47.65 & 145.84 & 110.90 \\
\hline CA1 & 16.71 & 12.00 & 40.67 & 359.61 & 97.33 \\
\hline Subiculum & 9.54 & 21.75 & 71.00 & 316.89 & 94.64 \\
\hline Amygdala & 18.12 & 24.56 & 61.53 & 212.13 & 132.14 \\
\hline \multicolumn{6}{|l|}{ Neocortex } \\
\hline Frontal Area BA 9 & 57.42 & 69.48 & 27.38 & 113.37 & 107.02 \\
\hline SMTG BA 21/22 & 37.90 & 46.53 & 65.33 & 157.53 & 160.39 \\
\hline Inf Parietal BA 40 & 96.87 & 107.15 & 35.70 & 107.97 & 114.49 \\
\hline Occipital BA 17-19 & 17.64 & 14.20 & 1.20 & 32.45 & 12.93 \\
\hline Readout $\rightarrow$ & $\begin{array}{c}\text { Positive pixels/ } \\
\mathrm{mm}^{2} / 10^{4}\end{array}$ & $\begin{array}{c}\text { Amyloid } \\
\text { Plaques } / \mathrm{mm}^{2}\end{array}$ & $\mathrm{NFTs} / \mathrm{mm}^{2}$ & $\begin{array}{l}\text { Positive } \\
\text { pixels/ } \\
\text { mm }^{2} / 10^{4}\end{array}$ & $\begin{array}{l}\text { 3+ pixels/ } \\
\mathrm{mm}^{2} / 10^{4}\end{array}$ \\
\hline
\end{tabular}

\begin{tabular}{|l|c|c|}
\hline ADNC & $\begin{array}{c}\text { This Patient's } \\
\text { Phase/Stage }\end{array}$ & $\begin{array}{c}\text { This Patient's } \\
\text { ADNC Score }\end{array}$ \\
\hline Amyloid & $\mathbf{4}$ & $\mathbf{3}$ \\
\hline Braak/NFT & $\mathbf{V I}$ & $\mathbf{3}$ \\
\hline CERAD/NP & Frequent & $\mathbf{3}$ \\
\hline
\end{tabular}

Overall High Level of AD NP Changes

Figure 1 Digital quantification of tau pathologies. (A) Analyses are performed on a paired helical filament-1 immunostained section. (B) After the crafted Genie neurofibrillary tangle/neuritic plaque (NFT/NP) algorithm was used to isolate the NFTs, the NFT density (NFTs/mm²) is determined by a modified nuclear algorithm, with NFT pseudo-colored yellow. (C) In a similar manner, the NP burden is calculated by first using the same crafted Genie algorithm to isolate the NPs, here pseudocolored orange. (D) An overall tau burden is also calculated: red: positive immunohistochemical (IHC) staining; blue: negative IHC staining. Scale bar, $25 \mu \mathrm{m}$. (E) A sample of the data that are provided in each pathology report from the University of Kentucky for a quantitative description of Alzheimer's disease (AD) pathology. ADNC, Alzheimer's disease neuropathologic change; CA1, hippocampus sector CA1; CERAD, Consortium to Establish a Registry for Alzheimer's Disease; Inf, inferior; SMTG, superior and middle temporal gyri.

for small-blood vessel profiles. Additionally, the new technology was applied to query neuroinflammation in animal models [45] by analyzing inflammatory cells in mice brains. These experiments included assessment of both quantitative neuroinflammatory changes (number of astrocytes or macrophages in a tissue) and qualitative changes (macrophage activation was addressed by querying macrophages in different morphologic states). Finally, digital 


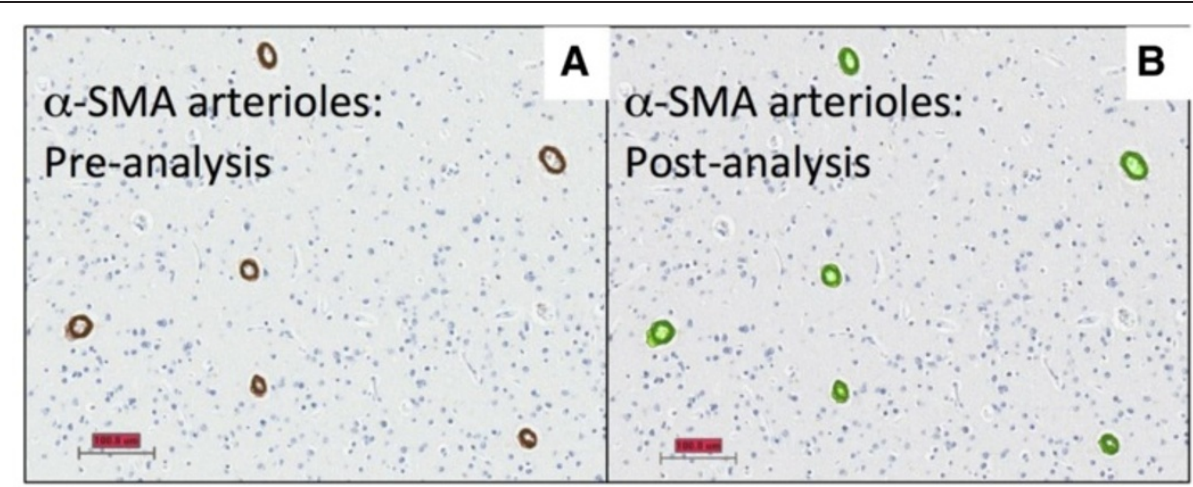

\section{Data from microvessel analysis}

Number of Vessels
Total Analysis Area (um2)
Total Stain Area (um2)
Average Stain Intensity
Microvessel Density -- \# of vessels per unit area (um2)
Mean Vessel Area (um2)
Median Vessel Area (um2)
Standard Deviation of Vessel Area (um2)
Mean Vessel Perimeter (um)
Median Vessel Perimeter (um)
Standard Deviation of Vessel Perimeter (um)
Mean Lumen Area (um2)
Median Lumen Area (um2)
Standard Deviation of Lumen Area (um2)
Mean Vascular Area (um2)
Median Vascular Area (um2)
Standard Deviation of Vascular Area (um2)
Mean Vessel Wall Thickness (um)
Median Vessel Wall Thickness (um)
Standard Deviation of Vessel Wall Thickness (um)

502

40010472.6

181610.1

100.707

1.25467e-005

408.008

189.

634.753

127.428

85.

157.096

60.6693

10.

196.974

350.062

176.

561.475

2.25328

2.02899

1.2738

Figure 2 Digital quantification in a brain section using alpha-smooth muscle actin (a-SMA) immunohistochemistry which labels arterioles. Actual immunohistochemical stain is brown (A) whereas the digital detection of those markers is pseudocolored green (B) after digital analyses were run. This is the basis for further in silico analyses of the blood vessel morphology. Scale bars, $100 \mu \mathrm{m}$. (C) A sample of the data that are collected from each analysis. Note that aspects of the blood vessel lumen, in addition to the lumen wall, are measured in a systematic way.

pathologic methods enable the study of larger areas of the brain and photomontages to depict multiple pathologic features in those brain areas [46]. Despite the benefits of the digital pathology methods, there are potential drawbacks. The cost of digital pathology could be problematic for some centers and hospitals: hundreds of thousands of dollars for a machine that also requires costly service contracts for future use (currently for the Aperio ScanScope used at the University of Kentucky, the service contract costs over $\$ 30,000$ USD per year). Furthermore, for a longitudinal study, there is always the question of whether that system will remain well supported by the manufacturer and whether future work will be directly comparable after the inevitable changes in technology. Whole slide analysis was the theoretical goal, but the massive amount of analysis time this required made this an impractical one. There are also specific areas of difficulty. For example, a challenging pathology to quantitate is the neuritic plaque. Owing to the heterogeneous nature of these lesions, single plaques are challenging to count individually. We note that the difficulty in this regard is also reflected by a general lack of consensus on what exactly defines these lesions (silver stain, thioflavine, or tau immunohistochemistry can be used). Also, there are drawbacks to the quantification of immunohistochemical phenomena because those phenomena can be labile to various technical factors, including fixation time and inevitable variabilities in chromagen development. 


\section{Automated microscopes}

Fully automated microscopes coupled to a personal computer (PC) and software represent another possibility to perform large-scale quantitative assessment. By conventional image analysis, photomicrographs are individually imported into the image analysis software, and subsequently adequate thresholds are set for measurement. Automated microscopes, on the other hand, may be entirely controlled by software allowing multiple images to be taken automatically; after a specific area of interest on the histological slide is set, multiple images covering this area are taken automatically and then combined into a single large image which is used for measurement (see $[47,48])$. As images need not be imported individually, this automated method is time-saving. Using this methodology, we could demonstrate that only the amount of neuronal cell loss in the substantia nigra correlated with reduced striatal ${ }^{123} \mathrm{I}$-FP-CIT SPECT (single-photon emission computed tomography) uptake but that the amount of hyperphosphorylated tau, $\mathrm{A} \beta$, and $\alpha$-synuclein in both striatum and substantia nigra had no influence on striatal ${ }^{123}$ I-FP-CIT SPECT uptake [47]. These findings were possible only by using a quantitative methodology as semi-quantitative assessment shows 'severe' nigral cell loss and 'severe' amounts of hyperphosphorylated tau, $A \beta$, and $\alpha$-synuclein pathology in most cases, making it impossible to detect any differences with regard to the amount of pathology in this study cohort. Recently, we could also demonstrate in human brain tissue that the amount of hyperphosphorylated tau pathology correlates with that of pyroglytamylated $A \beta$ but that no respective correlation was observed between hyperphosphorylated tau and non-pyroglutamylated $A \beta$ [48]. These findings suggest that pyroglytamylated $A \beta$ plays a crucial role in the pathogenesis of $\mathrm{AD}$. Automated microscopes can also be used to quantify pathology on tissue microarrays (TMAs); of note, TMA methodology is often used in cancer research in which one slide contains samples of many different cases. However, in the Newcastle Brain Tissue Resource (Newcastle University, UK), these TMAs are used to assess 40 different regions from any given case. Samples for TMAs from prefrontal (BA9), frontal (BA8), cingulate (BA32/24), motor (BA4), parietal (BA40/22), occipital (BA17), temporal (BA21), and entorhinal (BA28/ 27) cortices are taken from paraffin-embedded tissue blocks (previously used for conventional neuropathological assessment) by using a 3-mm tissue sampler (Tissue-Tek QuickRay TMA System; Sakura, Torrance, CA, USA), and a single, regular-sized $(40 \times 30 \times 5 \mathrm{~mm})$ paraffin block containing all 40 samples is produced. Sections from this TMA block are routinely stained with antibodies against hyperphosphorylated tau, $A \beta$, and $\alpha$-synuclein but are available for other immunohistochemical stains as well. To assess TMAs quantitatively, a so-called macro (that is, executive chain of commands) is created by using the image analysis software, NIS Elements (Nikon, Tokyo, Japan); 40 coordinates which correspond to the location of the TMA samples on the slide are set. The fully motorized Nikon 90i microscope is controlled entirely by PC/software, and with a $40 \times$ objective (400× magnification), the first acquisition of $3 \times 3$ images is performed in the center of the first TMA sample (top left). Image analysis is then performed automatically on the combined image, which represents an area of $1.7 \mathrm{~mm}^{2}$, using standardized thresholds: red-green-blue thresholds that determine the pixels that are included in the binary layer used for measurement are standardized separately for each immunostain (that is, hyperphosphorylated tau, $A \beta$, and $\alpha$-synuclein). We set the thresholds at a level that is reached by immunopositive pathological structures only (that is, NFTs, neuropil threads, $A \beta$ plaques/depositions, and LBs/neurites), but unspecific background staining and structures that do not show immunopositivity (for example, corpora amylacea) do not reach the threshold and thus are not included into the measurement.

The obtained data are automatically stored in a database. The microscope stage then moves automatically to allow image acquisition of the next TMA sample, and the procedure is repeated until images of all 40 samples are measured. Of note, before each image acquisition, autofocus is performed. The assessment of one TMA takes approximately 30 minutes and therefore is suited to be used in a routine setting. Of note, only the database containing the values of the areas covered by immunopositivity are kept on the $\mathrm{PC} /$ storage medium, whereas the images that were used for measurement are deleted (the original slides can be re-assessed if necessary). Hence, no extensive storage capacity is needed to keep the data. Using this methodology, we currently assessed over 100 post-mortem brains, including $\mathrm{AD}, \mathrm{LB}$ disease, and controls. One interesting finding was that the percentage area covered by immunopositivity (hyperphosphorylated tau, $A \beta$, and $\alpha$-synuclein) differed considerably within semiquantitative categories, in particular in areas that were semi-quantitatively scored 'severe', where, for example, the percentage area for hyperphosphorylated tau immunopositivity ranged from $10 \%$ to over $30 \%$. This further highlights the need for quantitative data in studies aiming to identify subtle and novel clinico-pathological phenotypes which may be characterized by the simultaneous presence of multiple pathologies.

\section{Conclusions}

Some recent discoveries were made possible only by using quantitative methodologies for the assessment of neuropathological lesions. We described some of the new methodologies that allow such a quantification at high throughput, but more methodologies are currently being 
developed. These techniques will enable the identification of new clinico-pathological phenotypes that reflect cerebral multi-morbidity of the aging brain. It is hoped that future studies identify specific clinical signs or biomarkers that more specifically point toward specific underlying neuropathologies, with respect to both their quantity and quality. Such studies are indeed warranted to allow an accurate stratification of patients in clinical trials and to further elucidate possible interactions between different pathological processes in the aging brain.

Note: This article is part of a series on Cerebral multi-morbidity of the aging brain edited by Johannes Attems and Julie

Schneider. Other articles in the series can be found at

http://alzres.com/series/cerebral_multimorbidity.

\section{Abbreviations}

ACT: Adult changes in thought; AD: Alzheimer's disease; ADNC: Alzheimer's disease neuropathologic change; AB: Amyloid-beta; LB: Lewy body; MRI: Magnetic resonance imaging; NFT: Neurofibrillary tangle; PC: Personal computer; SPECT: Single-photon emission computed tomography; TDP-43: Transactivation response DNA binding protein 43 kDa; TMA: Tissue microarray.

\section{Competing interests}

The authors declare that they have no competing interests.

\section{Authors' contributions}

All authors read and approved the final manuscript.

\section{Author details}

'Institute of Neuroscience, Newcastle University, Campus for Ageing and Vitality, Newcastle upon Tyne NE4 5PL, UK. ${ }^{2}$ Department of Pathology, Division of Neuropathology, University of Kentucky, 800 Limestone Street, Lexington, KY 40536-0230, USA.

\section{Published online: 28 November 2014}

\section{References}

1. Attems J, Jellinger K: Neuropathological correlates of cerebral multimorbidity. Curr Alzheimer Res 2013, 10:569-577.

2. Jellinger KA, Attems J: Neuropathological evaluation of mixed dementia. J Neurol Sci 2007, 257:80-87.

3. Jellinger KA, Attems J: Prevalence of dementia disorders in the oldest-old: an autopsy study. Acta Neuropathol 2010, 119:421-433.

4. Jellinger KA, Attems J: Prevalence and pathology of vascular dementia in the oldest-old. J Alzheimers Dis 2010, 21:1283-1298.

5. Kovacs GG, Alafuzoff I, Al-Sarraj S, Arzberger T, Bogdanovic N, Capellari S, Ferrer I, Gelpi E, Kovari V, Kretzschmar H, Nagy Z, Parchi P, Seilhean D, Soininen H, Troakes C, Budka H: Mixed brain pathologies in dementia: the BrainNet Europe consortium experience. Dement Geriatr Cogn Disord 2008, 26:343-350.

6. Kovacs GG, Milenkovic I, Wohrer A, Hoftberger R, Gelpi E, Haberler C, Honigschnabl S, Reiner-Concin A, Heinzl H, Jungwirth S, Krampla W, Fischer $\mathrm{P}$, Budka $\mathrm{H}$ : Non-Alzheimer neurodegenerative pathologies and their combinations are more frequent than commonly believed in the elderly brain: a community-based autopsy series. Acta Neuropathol 2013, 126:365-384.

7. Schneider JA, Arvanitakis Z, Bang W, Bennett DA: Mixed brain pathologies account for most dementia cases in community-dwelling older persons. Neurology 2007, 69:2197-2204.

8. Rahimi J, Kovacs GG: Prevalence of mixed pathologies in the aging brain. Alz Res Ther 2014, 6:82.
9. Nelson PT, Jicha GA, Schmitt FA, Liu H, Davis DG, Mendiondo MS, Abner EL, Markesbery WR: Clinicopathologic correlations in a large Alzheimer disease center autopsy cohort: neuritic plaques and neurofibrillary tangles 'do count' when staging disease severity. J Neuropathol Exp Neurol 2007, 66:1136-1146.

10. Nagy Z, Esiri MM, Jobst KA, Morris JH, King EM, McDonald B, Joachim C, Litchfield S, Barnetson L, Smith AD: The effects of additional pathology on the cognitive deficit in Alzheimer disease. J Neuropathol Exp Neurol 1997, 56:165-170.

11. Davidson YS, Raby S, Foulds PG, Robinson A, Thompson JC, Sikkink S, Yusuf I, Amin H, Duplessis D, Troakes C, Al-Sarraj S, Sloan C, Esiri MM, Prasher VP, Allsop D, Neary D, Pickering-Brown SM, Snowden JS, Mann DM: TDP-43 pathological changes in early onset familial and sporadic Alzheimer's disease, late onset Alzheimer's disease and Down's Syndrome: association with age, hippocampal sclerosis and clinical phenotype. Acta Neuropathol 2011, 122:703-713.

12. Uchikado H, Lin WL, DeLucia MW, Dickson DW: Alzheimer disease with amygdala Lewy bodies: a distinct form of alpha-synucleinopathy. J Neuropathol Exp Neurol 2006, 65:685-697.

13. Rauramaa T, Pikkarainen M, Englund E, Ince PG, Jellinger K, Paetau A, Alafuzoff I: TAR-DNA binding protein-43 and alterations in the hippocampus. J Neural Transm 2011, 118:683-689.

14. Josephs KA, Murray ME, Whitwell JL, Parisi JE, Petrucelli L, Jack CR, Petersen RC, Dickson DW: Staging TDP-43 pathology in Alzheimer's disease. Acta Neuropathol 2014, 127:441-450.

15. Josephs KA, Whitwell JL, Weigand SD, Murray ME, Tosakulwong N, Liesinger AM, Petrucelli L, Senjem ML, Knopman DS, Boeve BF, Ivnik RJ, Smith GE, Jack CR Jr, Parisi JE, Petersen RC, Dickson DW: TDP-43 is a key player in the clinical features associated with Alzheimer's disease. Acta Neuropathol 2014, 127:811-824.

16. Jellinger KA, Attems J: Prevalence and impact of vascular and Alzheimer pathologies in Lewy body disease. Acta Neuropathol 2008, 115:427-436.

17. Colom-Cadena M, Gelpi E, Charif S, Belbin O, Blesa R, Marti MJ, Clarimon J, Lleo A: Confluence of alpha-synuclein, tau, and beta-amyloid pathologies in dementia with Lewy bodies. J Neuropathol Exp Neurol 2013, 72:1203-1212.

18. Compta Y, Parkkinen L, O'Sullivan SS, Vandrovcova J, Holton JL, Collins C, Lashley T, Kallis C, Williams DR, de Silva R, Lees AJ, Revesz T: Lewy-and Alzheimer-type pathologies in Parkinson's disease dementia: which is more important? Brain 2011, 134:1493-1505.

19. Gaugler JE, Ascher-Svanum H, Roth DL, Fafowora T, Siderowf A, Beach TG: Characteristics of patients misdiagnosed with Alzheimer's disease and their medication use: an analysis of the NACC-UDS database. BMC Geriatr 2013, 13:137.

20. Alafuzoff I, Arzberger T, Al-Sarraj S, Bodi I, Bogdanovic N, Braak H, Bugiani O, Del-Tredici K, Ferrer I, Gelpi E, Giaccone G, Graeber MB, Ince P, Kamphorst W, King A, Korkolopoulou P, Kovacs GG, Larionov S, Meyronet D, Monoranu C, Parchi P, Patsouris E, Roggendorf W, Seilhean D, Tagliavini F, Stadelmann C, Streichenberger N, Thal DR, Wharton SB, Kretzschmar H: Staging of neurofibrillary pathology in Alzheimer's disease: a study of the BrainNet Europe Consortium. Brain Pathol 2008, 18:484-496.

21. Alafuzoff I, Ince PG, Arzberger T, Al-Sarraj S, Bell J, Bodi I, Bogdanovic N, Bugiani O, Ferrer I, Gelpi E, Gentleman S, Giaccone G, Ironside JW, Kavantzas N, King A, Korkolopoulou P, Kovacs GG, Meyronet D, Monoranu C, Parchi P, Parkkinen L, Patsouris E, Roggendorf W, Rozemuller A, Stadelmann-Nessler C, Streichenberger N, Thal DR, Kretzschmar H: Staging/typing of Lewy body related alpha-synuclein pathology: a study of the BrainNet Europe Consortium. Acta Neuropathol 2009, 117:635-652.

22. Murray ME, Graff-Radford NR, Ross OA, Petersen RC, Duara R, Dickson DW: Neuropathologically defined subtypes of Alzheimer's disease with distinct clinical characteristics: a retrospective study. Lancet Neurol 2011, 10:785-796

23. Whitwell JL, Dickson DW, Murray ME, Weigand SD, Tosakulwong N, Senjem ML, Knopman DS, Boeve BF, Parisi JE, Petersen RC, Jack CR Jr, Josephs KA: Neuroimaging correlates of pathologically defined subtypes of Alzheimer's disease: a case-control study. Lancet Neurol 2012, 11:868-877.

24. Janocko NJ, Brodersen KA, Soto-Ortolaza Al, Ross OA, Liesinger AM, Duara R, Graff-Radford NR, Dickson DW, Murray ME: Neuropathologically defined subtypes of Alzheimer's disease differ significantly from neurofibrillary tangle-predominant dementia. Acta Neuropathol 2012, 124:681-692.

25. Yen SH, Dickson DW, Crowe A, Butler M, Shelanski ML: Alzheimer's neurofibrillary tangles contain unique epitopes and epitopes in common 
with the heat-stable microtubule associated proteins tau and MAP2. Am J Pathol 1987, 126:81-91.

26. SantaCruz KS, Sonnen JA, Pezhouh MK, Desrosiers MF, Nelson PT, Tyas SL: Alzheimer disease pathology in subjects without dementia in 2 studies of aging: the Nun Study and the Adult Changes in Thought Study. I Neuropathol Exp Neurol 2011, 70:832-840.

27. Abner EL, Kryscio RJ, Schmitt FA, Santacruz KS, Jicha GA, Lin Y, Neltner JM, Smith CD, Van Eldik L, Nelson PT: 'End-stage' neurofibrillary tangle pathology in preclinical Alzheimer's disease: fact or fiction? J Alzheimers Dis 2011, 25:445-453.

28. Haroutunian V, Schnaider-Beeri M, Schmeidler J, Wysocki M, Purohit DP, Perl DP, Libow LS, Lesser GT, Maroukian M, Grossman HT: Role of the neuropathology of Alzheimer disease in dementia in the oldest-old. Arch Neurol 2008, 65:1211-1217.

29. Hyman BT, Phelps CH, Beach TG, Bigio EH, Cairns NJ, Carrillo MC, Dickson DW, Duyckaerts C, Frosch MP, Masliah E, Mirra SS, Nelson PT, Schneider JA, Thal DR, Thies B, Trojanowski JQ, Vinters HV, Montine TJ: National Institute on Aging Alzheimer's Association guidelines for the neuropathologic assessment of Alzheimer's disease. Alzheimers Dement 2012, 8:1-13.

30. Neltner JH, Abner EL, Schmitt FA, Denison SK, Anderson S, Patel E, Nelson PT: Digital pathology and image analysis for robust high-throughput quantitative assessment of Alzheimer disease neuropathologic changes. J Neuropathol Exp Neurol 2012, 71:1075-1085.

31. Nelson PT, Abner EL, Scheff SW, Schmitt FA, Kryscio RJ, Jicha GA, Smith CD, Patel E, Markesbery WR: Alzheimer's-type neuropathology in the precuneus is not increased relative to other areas of neocortex across a range of cognitive impairment. Neurosci Lett 2009, 450:336-339.

32. Nelson PT, Braak H, Markesbery WR: Neuropathology and cognitive impairment in Alzheimer disease: a complex but coherent relationship. J Neuropathol Exp Neurol 2009, 68:1-14.

33. Schmechel DE, Saunders AM, Strittmatter WJ, Crain BJ, Hulette CM, Joo SH, Pericak-Vance MA, Goldgaber D, Roses AD: Increased amyloid beta-peptide deposition in cerebral cortex as a consequence of apolipoprotein $\mathrm{E}$ genotype in late-onset Alzheimer disease. Proc Natl Acad Sci U S A 1993, 90:9649-9653.

34. Josephs KA, Tsuboi Y, Cookson N, Watt H, Dickson DW: Apolipoprotein E epsilon 4 is a determinant for Alzheimer-type pathologic features in tauopathies, synucleinopathies, and frontotemporal degeneration. Arch Neurol 2004, 61:1579-1584.

35. Drzezga A, Grimmer T, Henriksen G, Muhlau M, Perneczky R, Miederer I, Praus C, Sorg C, Wohlschlager A, Riemenschneider M, Wester HJ, Foerstl H, Schwaiger M, Kurz A: Effect of APOE genotype on amyloid plaque load and gray matter volume in Alzheimer disease. Neurology 2009, 72:1487-1494.

36. Caselli RJ, Walker D, Sue L, Sabbagh M, Beach T: Amyloid load in nondemented brains correlates with APOE e4. Neurosci Lett 2010, 473:168-171.

37. Nelson PT, Head E, Schmitt FA, Davis PR, Neltner JH, Jicha GA, Abner EL, Smith CD, Van Eldik $L$, Kryscio RJ, Scheff SW: Alzheimer's disease is not 'brain aging': neuropathological, genetic, and epidemiological human studies. Acta Neuropathol 2011, 121:571-587.

38. Jellinger KA, Attems J: Neuropathology and general autopsy findings in nondemented aged subjects. Clin Neuropathol 2012, 31:87-98.

39. Jicha GA, Abner EL, Schmitt FA, Kryscio RJ, Riley KP, Cooper GE, Stiles N, Mendiondo MS, Smith CD, Van Eldik LJ, Nelson PT: Preclinical AD Workgroup staging: pathological correlates and potential challenges. Neurobiol Aging 2012, 33:622.e1-622.e16.

40. Thal DR, von Arnim C, Griffin WS, Yamaguchi H, Mrak RE, Attems J, Rijal Upadhaya A: Pathology of clinical and preclinical Alzheimer's disease. Eur Arch Psychiatry Clin Neurosci 2013, 263:S137-S145.

41. Nelson PT, Abner EL, Schmitt FA, Kryscio RJ, Jicha GA, Smith CD, Davis DG, Poduska JW, Patel E, Mendiondo MS, Markesbery WR: Modeling the association between 43 different clinical and pathological variables and the severity of cognitive impairment in a large autopsy cohort of elderly persons. Brain Pathol 2008, 20:66-79.

42. Jellinger KA, Attems J: Is there pure vascular dementia in old age? J Neurol Sci 2010, 299:150-154.

43. Neltner JH, Abner EL, Baker S, Schmitt FA, Kryscio RJ, Jicha GA, Smith CD, Hammack E, Kukull WA, Brenowitz WD, Van Eldik LJ, Nelson PT: Arteriolosclerosis that affects multiple brain regions is linked to hippocampal sclerosis of ageing. Brain 2014, 137:255-267.
44. Nelson PT, Schmitt FA, Lin Y, Abner EL, Jicha GA, Patel E, Thomason PC, Neltner JH, Smith CD, Santacruz KS, Sonnen JA, Poon LW, Gearing M, Green RC, Woodard JL, Van Eldik LJ, Kryscio RJ: Hippocampal sclerosis in advanced age: clinical and pathological features. Brain 2011, 134:1506-1518.

45. Bachstetter AD, Norris CM, Sompol P, Wilcock DM, Goulding D, Neltner JH, St Clair D, Watterson DM, Van Eldik LJ: Early stage drug treatment that normalizes proinflammatory cytokine production attenuates synaptic dysfunction in a mouse model that exhibits age-dependent progression of Alzheimer's disease-related pathology. J Neurosci 2012, 32:10201-10210.

46. Nelson PT, Smith CD, Abner EL, Wilfred BJ, Wang WX, Neltner JH, Baker M, Fardo DW, Kryscio RJ, Scheff SW, Jicha GA, Jellinger KA, Van Eldik LJ, Schmitt FA: Hippocampal sclerosis of aging, a prevalent and high-morbidity brain disease. Acta Neuropathol 2013, 126:161-177.

47. Colloby SJ, McParland S, O'Brien JT, Attems J: Neuropathological correlates of dopaminergic imaging in Alzheimer's disease and Lewy body dementias. Brain 2012, 135:2798-2808.

48. Mandler M, Walker L, Santic R, Hanson P, Upadhaya AR, Colloby SJ, Morris CM, Thal DR, Thomas AJ, Schneeberger A, Attems J: Pyroglutamylated amyloid-beta is associated with hyperphosphorylated tau and severity of Alzheimer's disease. Acta Neuropathol 2014, 128:67-79.

doi:10.1186/s13195-014-0085-y

Cite this article as: Attems et al:: Quantitative neuropathological assessment to investigate cerebral multi-morbidity. Alzheimer's Research \& Therapy $20146: 85$. 